\title{
EVALUATION OF SPECIFIC ABSORPTION RATE AMONG PATIENTS USING 3 TESLA AND 1.5 TESLA MAGNETIC RESONANCE IMAGING MACHINES
}

\author{
Supakajee Saengruang-Orn, Busabong Noola
}

\section{Department of Radiology, Phramongkutklao Hospital, Thailand.}

\begin{abstract}
Background: Specific Absorption Rate (SAR) is radiofrequency power delivered to tissue during a Magnetic Resonance Imaging (MRI) examination, expressed as watts per $\mathrm{kg}(\mathrm{W} / \mathrm{kg}$ ). Radiofrequency power deposition results in increased heating of patient tissues; thus, the use of MRI has to be controlled to ensure patient safety.

Objective: The study aimed to evaluate SAR among patients using the 3 Tesla MRI (MRI 3T) and 1.5 Tesla MRI (MRI 1.5T) machines.

Methods: Data were obtained from patients who were examined using MRI 3T (1,159 patients, 8,225 series) and MRI 1.5T (1,423 patients, 8,605 series) machines. Age, body weight, SAR, repetition time (TR), type of radiofrequency (RF) pulse and anatomical region exposed were studied.

Results: Average SAR for all patients using the MRI 3T was lower than that of the MR 1.5T in every part $(p<0.001)=0.92 \pm 0.57 \mathrm{~W} / \mathrm{Kg}, 2.45 \pm 1.01 \mathrm{~W} / \mathrm{Kg}$, accordingly. The SAR that the patients received using the spin echo technique revealed that T2 weighted image had lower SAR than T1 weighted image from both MRI 3T and MRI 1.5T ( $p<0.001), 0.87$ and $0.98 \mathrm{~W} / \mathrm{kg}$ for MRI 3T, 2.20 and 2.83 W/kg for MRI 1.5T, respectively. For underweight patients, the lowest SAR was $0.89 \mathrm{~W} / \mathrm{Kg}$ (MRI 3T) and 2.40 $\mathrm{W} / \mathrm{Kg}$ (MRI 1.5T), respectively. Whereas, among overweight patients, the SAR was the highest at 0.97 $\mathrm{W} / \mathrm{Kg}$ (MRI 3T) and 2.52 W/Kg (MRI 1.5T). For SAR categorized by the flip angle of the RF pulse, and patients evaluated by the MRI 3T, the study revealed that the group with the flip angle of the RF pulse $<75$ degrees had lower SAR than the flip angle of the RF pulse $>75$ degrees, $0.77 \mathrm{~W} / \mathrm{Kg}$ and 0.94 $\mathrm{W} / \mathrm{Kg}$, accordingly $(p<0.001)$ similar to the MRI $1.5 \mathrm{~T}$.

Conclusion: The average SAR of patients evaluated using the MRI 3T was lower than those of patients evaluated using the MRI 1.5T in every body part examined. SAR was lower when the TR was increased and flip angle was decreased.
\end{abstract}

Keywords: Specific Absorption Rate (SAR), 3 Tesla MRI machine, 1.5 Tesla MRI machine

J Southeast Asian Med Res 2020; 4(1):41-47

http://www.jseamed.org

Correspondence to: Saengruang-Orn S., Department of Radiology, Phramongkutklao Hospital, 315 Rachawithi Rd., Rachathewi District, Bangkok 10400, Thailand.

Phone: 095-947-2410 Fax: 02-354-5243

E-mail: S_supakajee@yahoo.com

Received: 2019-08-27

Revised: 2020-02-15

Accepted: 2020-05-12 


\section{Introduction}

The magnetic resonance imaging (MRI) machine is an important diagnostic tool generating imaging using an electromagnetic field and the spinning of the nucleus of the hydrogen atom which is the fundamental composition in the human body such as in the water molecule $\left(\mathrm{H}_{2} \mathrm{O}\right)$. The magnet embedded within the MRI scanner can act on these positively charged hydrogen ions $\left(\mathrm{H}^{+}\right.$ions $)$and cause them to 'spin' in an identical manner. Varying the strength and direction of this magnetic field can change the direction of the 'spin' of the protons, enabling us to build layers of detail. When a patient enters the MRI machine, it would transmit a radiofrequency $(\mathrm{RF})$ wave at a specific radio frequency transforming into heat within the patients' tissue. When the magnet is switched off, the protons will gradually return to their original state in a process known as precession. Fundamentally, the different tissue types within the body return at different rates allowing us to visualize and differentiate between the different tissues of the body to distinctly detect abnormalities for diagnosis.

As the electromagnetic radiation that is used is the non-ionizing radiation, the energy of the radio waves is not sufficiently high to cause the disintegration of the charges in the atoms or molecules ${ }^{(1)}$. However, related studies have indicated that electromagnetic waves alter the body's biology and affects vision, hearing, the endocrine system, the nervous system, the cardiovascular system, the immune system and the reproductive system. These biological alterations occur due to the induction of heat from the electromagnetic waves that the body receives, ${ }^{(2-11)}$ which are used to create MR images, most significantly from the induction of the magnetic fields ${ }^{(12-21)}$. The rise in the body temperature of the patients by the electromagnetic waves, depends on several factors related to the regulation of body temperature and control of the environment ${ }^{(3-8)}$. The temperature changes and other body changes from the reception of electromagnetic waves depend upon the amount of energy that the body absorbs, called the specific absorption rate (SAR) ${ }^{(2-4)}$. This is the value that depicts the amount of heat per mass of the tissue or the body part that is receiving the energy from electromagnetic waves. This value is measured in watts $/ \mathrm{kg}(\mathrm{W} / \mathrm{kg})^{(2-4)}$ and constitutes a factor affecting the calculation of SAR while the MRI is obtained including, but not limited to, the flip angle of the RF pulse, the repetition time (TR), the type of the RF coil, the anatomical region exposed and the patient's body weight ${ }^{(19-22)}$.

The Food and Drug Administration (FDA) ${ }^{(23)}$ has recommended that the SAR should not exceed the value indicated below to decrease the risks involved from using radio waves on the patient. The average SAR of the body should not exceed $4 \mathrm{~W} / \mathrm{kg}$ in 15 minutes, the average SAR of the head should not exceed $3 \mathrm{~W} / \mathrm{kg}$ in 10 minutes, the average SAR of the head and body should not exceed $8 \mathrm{~W} / \mathrm{kg}$ in 5 minutes and the average SAR of the arms should not exceed $12 \mathrm{~W} / \mathrm{kg}$ in 5 minutes. Therefore, MRI machines have been programmed, to be alerted to and immediately terminate when the patient is being examined using the MRI machine and the SAR exceeds the set limits ${ }^{(23)}$. The study aimed to compare the SAR recorded among patients undergoing MRI using MRI 3T and MRI 1.5T machines. The result of this study would help to adjust the parameters used for the MRI machine to evaluate patients to further increase safety and efficacy of the MRI.

\section{Methods}

This study employed a retrospective descriptive study design approved by the Ethics Committee, Institutional Review Board, Royal Thai Army Medical Department (S013h/61). The inclusion criteria comprised data sets including the parameters SAR, age, weight, SAR, repetition time, type of RF pulse and anatomical region exposed recorded from the MRI studies and information only obtained from patients who were 16 years of age or above. The exclusion criteria included any incomplete data sets that did not have all required information on the parameters. The appropriate sample size calculated for each MRI machine was at least 8,182 series of images. Simple random sampling was employed using computer generated simple random samples from data sets from both MRI machines obtained from January to December 2018.

Collecting data from patients evaluated using the MRI 3T model Philips Achieva 3.0T TX (1,159 patients, 8,225 series) and 1.5 T model Philips Achieva 1.5T XR (1,423 patients, 8,605 series) using the DoseMonitor Program by PACSHealth, LLC included age, body weight and specific absorption rate (SAR), repetition time (TR), type 
of RF pulse and anatomical region exposed. Data acquisition was achieved by sending Digital Imaging and Communications in Medicine (DICOM) of the MRI to the Dose Monitor Program. The program obtained the data from the DICOM header and exported the data in the form of an Excel file.

The SAR values, as estimated by the MR system console, were noted from the DICOM, allowing the data to be categorized in two groups of body weight based on the Thai body shape and body database (SizeThailand) ${ }^{(24)}$. The range of the body weight used was the normal weight range of the average weight of Thai men and women $\pm 5 \mathrm{~kg}$. The age group was divided and subdivided in underweight patients $(<58 \mathrm{~kg})$, normal weight (58-68 kg) and overweight $(>68 \mathrm{~kg})$, SAR and TR. The patients with T1 weight image in spin echo pulse sequence (SE) would have TR $<800 \mathrm{msec}$ and those with T2 weight image SE would have TR $>2,500 \mathrm{msec}^{(25)}$. Data also included the flip angle of the RF pulse divided in a group with flip angle $<75$ degrees and a group with flip angle $>75$ degrees.
The statistics used included mean and standard deviation. For qualitative analysis, the data included the type of coil and the anatomical region exposed; which were divided into the head and neck, spine, abdomen and extremities; as percentile. To compare differences between the SAR among patients evaluated using the MRI 3T versus those that were evaluated using the MRI 1.5T; the unpaired t-test was used to compare the means of two unmatched groups, and one-way analysis of variance (ANOVA) was used to determine any statistically significant differences between three independent groups, where the level of significance was 0.05 .

\section{Results}

The demographic information of the patients who had undergone MRI using the MRI 3T machine revealed mean age of $44.82 \pm 19.66$ years and mean body weight of $65.45 \pm 14.59 \mathrm{~kg}$. In total, 8,225 series of images were divided into 2,551 series of head and neck images, 2,142 series of spine images and 3,532 series of extremities images as shown in Table 1.

Table1. Demographics of participants imaged with 3 Tesla MRI and 1.5 Tesla MRI of each organ

\begin{tabular}{lccc}
\hline \multicolumn{1}{c}{ Variables } & \multicolumn{3}{c}{ Magnetic Field Strength } \\
\cline { 2 - 4 } & $\mathrm{N}=8,225$ Series & $\mathrm{N}=8,605$ series & $p$-value \\
\hline Gender (\%) & $\begin{array}{c}\text { Male=4,761 } \\
(57.88)\end{array}$ & Male $=4,557(52.96)$ & \\
& Female=4,048 (47.04) & $<0.001$ \\
& $(42.12)$ & & \\
Age Years, Mean (SD) & $44.82(19.66)$ & $54.63(17.39)$ & $<0.001$ \\
& & & \\
Weight kg. Mean (SD) & $65.45(14.59)$ & $63.27(12.07)$ & $<0.001$ \\
& & & $<0.001$ \\
Anatomical region exposed: & & & $<0.001$ \\
Head \& Neck & 2,551 & 2,443 & $<0.001$ \\
Spine & 2,142 & 2,225 & \\
Extremities & 3,532 & 3,937 & \\
& & & \\
\end{tabular}

Note: $\mathrm{n}=$ number of series of images 
The general demographic information of the patients that had undergone MRI in the $1.5 \mathrm{~T}$ machine revealed mean age of $54.63 \pm 17.39$ years and mean body weight of $63.27 \pm 12.07 \mathrm{~kg}$. In total 8,605 series of images were divided into 2,443 series of head and neckimages, 2,225 series of spine images and 3,937 series of extremities images.

The average SAR of all the patients that had been evaluated using the $3 \mathrm{~T}$ MRI machine was significantly lower that the SAR of those that had been evaluated using the 1.5T MRI machine $(p<0.001) \mathrm{SAR}=0.92 \pm 0.57 \mathrm{~W} / \mathrm{Kg}$ and $2.45 \pm$ $1.01 \mathrm{~W} / \mathrm{Kg}$, accordingly. When categorized and analyzed according to the anatomical regions exposed, patients that had been evaluated using the $3 \mathrm{~T}$ and the $1.5 \mathrm{~T}$ machines showed the least SAR in the head and neck studies and the SAR from the $3 \mathrm{~T}$ machine was significantly lower than the $1.5 \mathrm{~T}$ machine, $\mathrm{p}$-value $<0.001) \mathrm{SAR}=$ $0.21 \pm 0.20 \mathrm{~W} / \mathrm{kg}$ and $1.87 \pm 1.05 \mathrm{~W} / \mathrm{kg}$, accordingly. The anatomic region exposed having the highest SAR among the patients that were evaluated by the $3 \mathrm{~T}$ machine was the spine $=$ $1.39 \pm 0.37 \mathrm{~W} / \mathrm{kg}$ whereas the anatomic region exposed that had the highest SAR among the patients that were evaluated by the $1.5 \mathrm{~T}$ machine was the extremities $=2.80 \pm 0.84 \mathrm{~W} / \mathrm{kg}$ as shown in Table 2.

SAR for patients who were imaged using the spin echo technique found that T2 weight image (long TR $>2500 \mathrm{msec}$ ) had significantly higher SAR than T1 weight image (short TR $<800 \mathrm{msec}$ ) in both MRI 3T and the MRI 1.5T machines $(p<0.001), 0.98$ and 0.87 and $0.98 \mathrm{~W} /$ $\mathrm{kg}$ for $3 \mathrm{~T}, 2.20$ and $2.83 \mathrm{~W} / \mathrm{kg}$ for $1.5 \mathrm{~T}$. When considering the SAR value by weight groups, the underweight group $(<58 \mathrm{~kg})$ had the lowest SAR $=0.89 \mathrm{~W} / \mathrm{kg}$ (MRI 3T), $2.40 \mathrm{~W} / \mathrm{kg}$ (MRI 1.5T) and the overweight group ( $>68 \mathrm{~kg}$ ) had the highest SAR $=0.97 \mathrm{~W} / \mathrm{kg}$ (MRI 3T), $2.52 \mathrm{~W} / \mathrm{kg}$ (MRI 1.5T). When comparing the SAR the patient received from the MRI 3T machine, the SAR in the underweight $(0.89 \mathrm{~W} / \mathrm{kg})$, normal weight $(0.90 \mathrm{~W} / \mathrm{Kg})$ and overweight $(0.97 \mathrm{~W} / \mathrm{Kg})$ groups significantly differed $(p<0.001)$. When comparing the SAR that patients received from the $1.5 \mathrm{~T}$ MRI machine, the SAR of the underweight (2.40 $\mathrm{W} / \mathrm{Kg}$ ), normal weight $(2.44 \mathrm{~W} / \mathrm{Kg}$ ) and overweight $(2.52 \mathrm{~W} / \mathrm{Kg})$ groups significantly differed $(p<$ 0.001 ) as shown in Table 3.

When analyzing the SAR categorized by the flip angle of the RF pulse among patients examined by the $3 \mathrm{~T}$ MRI machine, the group with the flip angle of the RF pulse $<75$ degrees received significantly less SAR than the group with the flip angle of the RF pulse $>75$ degrees, which were $0.77 \mathrm{~W} / \mathrm{kg}$ and $0.94 \mathrm{~W} / \mathrm{kg}$, accordingly $(p=0.001)$. Similarly, among patients examined using the 1.5T MRI machine, the group with the flip angle of the RF pulse $<75$ degrees received significantly less SAR than the group with the flip angle of the RF pulse $>75$ degrees, i.e., 2.18 $\mathrm{W} / \mathrm{kg}$ and $2.48 \mathrm{~W} / \mathrm{kg}$, accordingly $(p=0.001)$.

Table 2. Specific absorption rates among patients evaluated using the $3 \mathrm{~T}$ and $1.5 \mathrm{MRI}$ machines

\begin{tabular}{lccc}
\hline \multicolumn{1}{c}{ Variables } & \multicolumn{2}{c}{ Specific absorption rate (SAR)/ Type of coil } \\
\cline { 2 - 4 } & 3 Tesla $($ mean \pm SD) & 1.5 Tesla (mean \pm SD) & $p$-value \\
\hline Anatomical region exposed: & & & \\
Head \& Neck & $0.21 \pm 0.20$ & $1.87 \pm 1.05$ & $<0.001$ \\
Spine & $1.39 \pm 0.37$ & $2.41 \pm 0.90$ & $<0.001$ \\
Extremities & $1.09 \pm 0.30$ & $2.80 \pm 0.84$ & $<0.001$ \\
& & & $<0.001$ \\
\hline
\end{tabular}


Table 3. Specific absorption rate (SAR) of each parameter used for patients who were evaluated using the $3 \mathrm{~T}$ and $1.5 \mathrm{MRI}$ machines

\begin{tabular}{ccccc}
\hline \multicolumn{1}{c}{ Variables } & \multicolumn{2}{c}{3 Tesla $(\mathrm{n}=8,225)$} & \multicolumn{1}{c}{1.5 Tesla $(\mathrm{n}=8,605)$} \\
\cline { 2 - 4 } & SAR & $p$-value & SAR & $p$-value \\
\hline Type of Image & & & & \\
T1 weighted Image (TR $<700 \mathrm{msec})$ & $0.93(\mathrm{n}=3,319)$ & & $2.83(\mathrm{n}=3,344)$ & \\
T2 weighted Image (TR $>2,500 \mathrm{msec})$ & $0.87(\mathrm{n}=4,906)$ & $<0.001$ & $2.20(\mathrm{n}=5,261)$ & $<0.001$
\end{tabular}

Weight Group

Under weighted ( $<58 \mathrm{~kg}$.)

Normal weighted $(58-68 \mathrm{~kg}$.)

$0.89(\mathrm{n}=2,620)$

$2.40(\mathrm{n}=2,652)$

Over weighted ( $>68 \mathrm{~kg}$.)

$0.97(\mathrm{n}=2,561)$

$2.44(n=3,331)$

$0.90(\mathrm{n}=3,044)<0.001 \quad 2.52(\mathrm{n}=2,622)$

$<0.001$

Flip angle of RF Pulse
$<75$ degree
$>75$ degree

$0.77(\mathrm{n}=1,113)$

$0.94(\mathrm{n}=7,112) \quad<0.001$

$2.18(\mathrm{n}=715)$

$2.52(\mathrm{n}=7,890) \quad<0.001$

Note: $\mathrm{n}=$ number of series of images

\section{Discussion}

The average SAR value for all patients evaluated using the 3T MRI machine was lower than that of patients evaluated using the 1.5T MRI machine. This coincides with the study by Krishnamurthy ${ }^{(26)}$ reporting that fetal brain images with higher resolution and better SNR with MRI 3.0T exhibited simultaneously reduced SAR compared with MRI 1.5T. In addition, the SAR received by the patients did not exceed the SAR limits set by FDA $^{(23)}$ which recommends that SAR for the whole body study should be lower than $4 \mathrm{~W} / \mathrm{kg}$ within 15 minutes, for the head and neck should be lower than $3 \mathrm{~W} / \mathrm{kg}$ within 10 minutes and for the extremities should be lower than $12 \mathrm{~W} / \mathrm{kg}$ within 5 minutes; to decrease the possible effects on the patient's tissues from the radio waves used in the MRI.

The SAR in studies where the spin echo technique was used showed that $\mathrm{T} 2$ weighted image (long TR $>2,500$ music) had lower SAR than T1 weighted image (short TR $<800 \mathrm{msec}$ ) similar to the study by Allision et al. ${ }^{(27)}$ and Chavhan et al. ${ }^{(28)}$ showing that SAR decreased when TR increased. When considering the SAR according to weight group, for the underweight patients $(<58 \mathrm{~kg})$, the SAR was the lowest, $0.89 \mathrm{~W} / \mathrm{kg}(3 \mathrm{~T}), 2.40 \mathrm{~W} / \mathrm{kg}$ $(1.5 \mathrm{~T})$ and for the overweight patients $(>68 \mathrm{~kg})$
SAR was the highest $=0.97 \mathrm{~W} / \mathrm{kg}(3 \mathrm{~T}), 2.52 \mathrm{~W} /$ $\mathrm{kg}(1.5 \mathrm{~T})$. This coincides with the study by Gach et al. ${ }^{(29)}$ revealing obese patients had a higher risk of absorbing heat from MRI than non-obese patients because obese patients required more field of view to scan.

When analyzing SAR according to the flip angle of the RF pulse, patients who were examined with the flip angle of the RF angle $<75$ degrees received less SAR than those examined with the flip angle of the RF pulse $>75$ degrees. This coincides with the study by Allison et al. ${ }^{(27)}$ and Chavhan et al. ${ }^{(28)}$ showing the SAR decreased when the flip angle decreased. The results of this study could help radiologists and MR technologists to experience greater confidence regarding the information that the SAR received by the patients not exceeding the SAR limits set by the FDA. In addition, the SAR decreased with decreased flip angle and increased TR.

\section{Conclusion}

The study revealed the average SAR of all patients, evaluated using the 3T MRI machine, was lower than those investigated using the 1.5T MRI machine for every anatomical region examined. For both of the MRI 3T and the MRI 1.5T groups, patients undergoing head and neck 
studies would have the lowest SAR. Overweight patients would receive higher SAR. SAR could be reduced when TR increased and the flip angle decreased.

\section{Acknowledgements}

We would like to express our gratitude to Dr. Narongchai Sriasavaamorn, the Director of the Department of Radiology, Phramongkutklao Hospital, for research support. We would also like to thank Dr Chalita Sakchiraphong for English writing and also Mr Prasitpong Thirayothin for information analysis. In addition, the researcher would like to thank all MRI technologists at Phramongkutklao Hospital for providing all patients' parameters.

\section{Potential conflicts of interest}

The authors declare they have no conflict of interest.

\section{References}

1. Saiviroonporn P. MRI: Principle and Safety. Bangkok. Wattana Printing Factory. 2008.

2. National Council on Radiation Protection and Measurements. Biological effects and exposure criteria for radiofrequency electromagnetic fields. Report No. 86. Bethesda, MD: National Council on Radiation Protection and Measurements; 1986.

3. GordonCJ.Thermal physiology. In:Biological effects of radiofrequency radiation. Washington, DC:EPA-600/8-83-0264A; 1984.

4. Gordon CJ. Effect of Radiofrequency radiation exposure on thermo-regulation. ISI Atlas Sci Plants Anim 1988; 1: 245-50.

5. Michaelson SM, Lin JC. Biological effects and health implications of radiofrequency radiation. New York: Plenum 1987.

6. Adey WR. Tissue interactions with nonionizing electromagnetic fields. Physiol Rev 1981; 61: 435-514.

7. Elder JA. Special senses. In: biological effects of radiofrequency radiation. Washington, DC: EPA-600/8-83-26A;1984.

8. Berman E. Reproductive effects. In: biological effects of radiofrequency radiation. Washington, DC:EPA-600/8-83-026A;1984.

9. U.S. Environmental Protection Agency. Evaluation of potential electromagnetic carcinogenicity. Office of Health and Environmental Assessment. Washington, DC:EPA-600/6-90-005A;1990.

10. Conner ME. Mammalian teratogenesis and radio-frequency fields. Proc IEEE 1980; 68: 56-60.

11. Lary JM, Conover DL. Teratogenic effects of radiofrequency radiation. IEEE Eng Med Biol 1987; 44: 42-6.

12. Edelman RR, Shellock FG, Ahladis J. Practical MRI for the technologist and imaging specialist. In: Edelman RR, Hesselink J, eds. Clinical magnetic resonance. Philandelphia: WB Saunders 1990.

13. Persson BRR, Stahlberg F. Health and safety of clinical NMR examinations. Boca Raton, FL: CRC Press 1989: 59-79.

14. Shellock FG, Kanal E. Magnetic Resonance: bioeffects, safety, and patient management, 2nd ed. New York: Lippincott-Raven 1996: 25-48.

15. Shellock FG. Biological effects and safety aspects of magnetic resonance imaging. Magn Reson Q 1989; 5: 243-61

16. Kanal E, Shellock FG, Talagala L. Safety considerations in MR imaging. Radiology 1990; 176: 593-606.

17. Morvan D, Leroy-Willig A, Jehenson P, Cuenod CA, Syrota A. Temperature changes induced in human muscle by rsiofrequency $\mathrm{H} 01$ coplinf: measurement with an MR imaging diffusion technique. Radiology. 1992; 185: 871-4.

18. Shellock FG. MRI bioeffects and safety. In: Atlas S, ed. Magnetic resonance imaging of the brain and spine. New York: Raven Press 1990.

19. Shellock FG. Thermal responses in human subjects exposed to magnetic resonance imaging. Ann NY Acad Sci 1992: 260-72.

20. Bottomley PA, Edelstein WA. Power deposition in whole body NMR imaging. Med Phys 1981; 8: 510-2.

21. Shellock FG, Liwer C, Kanal E. MRI bioeffects, safety, and patient management: a review. Rev Magn Reson Imaging 1992; 4: 21-63.

22. Beers J. Biological effects of weak electromagnetic fields from $0 \mathrm{~Hz}$ to $200 \mathrm{MHz}$ : a survey of the literature with special emphasis on possible magnetic resonance effects. Magn Reson Imaging 1989; 7: 309-31. 
23. United States Food and Drug Administration. Criteria for significant risk investigations of Magnetic Resonance diagnostic devices. 2003, at URL http//www.fda.gov/cdrh /ode/ guidance/793.pdf.

24. National Electronics and Computer Techno logy Center. SizeThailand. [online] 2018 [cited 2019 Jan 8] Available from: URL: http:// www.sizethailand.org/region_all.html

25. Kang O, Skalski M. MRI Sequence Parameters. [online] 2018 [cited 2019 April 8] Available from: URL: https://radiopaedia. org/articles/mri-sequence-parameters.

26. Krishnamurthy U, Neelavalli J, Mody S, Yeo L, Jella PK, Saleem S, et al. MR imaging of the fetal strengths: comparing specific absorption rate (SAR) and image quality. J Perinat Med [online] 2018 [cited 2019 May8] Available from: URL: https://www.ncbi. nlm.nih. gov/ pmc/articles/PMC5987203/\#

27. Allison J, Yanasak N. What MRI sequence produce the highest specific absorption rate, and is there something we should be doing to reduce the SAR during standard examinations? Am J Roentgenol 2015; 205:W140.

28. Chavhan GB, Babyn PS, Singh M, Vidarsson L, Shroff M. MR Imaging at 3.0 T in children; technical differences, safety issues, and initial experience. Radiographics 2009; 29: 1453.

29. Gach HM, Mackey SL, Hausman SE, Danielle R J, Benzinger TL, Henke L, et al. MRI safety risks in the obese: The case of the disposable lighter stored in the pannus. Radiol Case Rep 2019; 14: 634-8. 